\title{
Agency in action - young women and their sexual relationships in a private school
}

Claire Maxwell and Peter Aggleton

\begin{abstract}
Agency among young women is often understood as fleeting in nature, and studies rarely offer insights into how agency could become a more sustained position. Using data from 54 young women discussing their sexual and intimate relationships, this paper suggests a new way of understanding agency beyond that found in work which stresses agentic practice as resistance or the challenging of dominant expectations and understandings. Instead, through the notion of 'agency in action' we begin with young women's conceptualisations of power. In this study, power was viewed as a resource that is shared between partners, but also a capacity of the self. These conceptualisations offer two new ways of understanding agency in intimate relations - either through 'reacting into action' and taking power back; or by 'starting from' a powerful position. Central to an understanding of young women's agency is the role of emotions and recognition of these as motivators for change.
\end{abstract}

Keywords: sexuality; gender; femininities; agency; emotion

Published in Gender and Education, 22(3): 327-343. 
Maxwell, C. and Aggleton, P. (2010) 'Agency in action - young women and their sexual relationships in a private school', Gender and Education, 22(3): 327-343.

\section{Introduction}

Over the last decade, there has been growing interest in how young women 'manage' their sexual experiences and intimate relationships (Allen 2003; Holland et al. 1998; Maxwell 2007). Specifically, some researchers have worked to develop understandings of how young women feel powerful within their sexual relationships and how they articulate their needs and desires. Early literature often used the term 'empowerment' (Holland et al. 1998), but later work has increasingly engaged with post-structuralist understandings (Allen 2003) to deploy notions of agency and agentic practice. However, the concept of agency has a broader heritage and is variously employed across the spectrum of sociological theory (Barnes 2000; Clegg 2006; McNay 2000, 2008; Sewell 1992).

Agency has been described as a 'slippery' term (Hitlin and Elder 2007, 170) and a 'source of increasing strain and confusion in social thought' (Emirbayer and Mische 1998, 962). We begin therefore by seeking to examine how the concept of agency is understood by two dominant frameworks informing current theorisation of young femininities and sexualities. In this respect, a number of researchers have found a Butlerian framework very productive (see, for example, Allen 2008; Beavis and Charles 2007; Youdell 2005), while others favour the understandings of agency which emerge from the use of Bourdieu's concepts of the habitus and field (see, for example, Allard 2005; Thomson 2000).

Yet beyond these general frameworks there may be other starting points for looking at agency - namely those grounded in young women's own conceptualisations of power. Drawing on findings from a recent study conducted with a group of young women (aged 1618 years) in a co-educational private school in England, this paper therefore seeks to offer a 'third way' to understanding agency through young women's narratives of 'agency in action'.

\section{Agency within a Butlerian framework}

According to Judith Butler (1997), a subject becomes intelligible through interpellation or the process of being named. Interpellation occurs through a series of rituals (which may include the way in which someone moves, talks, dresses and interacts with others) and the self becomes constituted through discourse. This process has also been described as the performative constitution of the subject (Butler 1990). Discursive agency (Butler 1997, 127) occurs when the subject who has been so named (for instance, as a girl) is then able to name another (1997, 29), through utterances and bodily practices (Youdell 2006). While recurring citations of gender usually lead to the replication of the heterosexual matrix (Butler 1990), 'performative utterances can go wrong, be misapplied or misinvoked' (Butler 1997, 151). Such misfiring need not be intentional (Youdell 2005). Butler (1997) argues that through discursive agency comes the possibility for a politics of performative resignification. Notions of femininity can potentially be 'reformulated' (Beavis and Charles 2007, 691) or misappropriated (Butler 1997).

How have researchers drawn on a Butlerian framework to make sense of agentic practice among young women? Drawing on her field notes Youdell illustrates how Pipa, a white, middle-class young woman in a predominantly working-class school, uses 'discursive 
Maxwell, C. and Aggleton, P. (2010) 'Agency in action - young women and their sexual relationships in a private school', Gender and Education, 22(3): 327-343.

resources that render alternative hetero-feminine ... subjectivities both intelligible and legitimate' $(2005,268)$. One episode recounted by Youdell finds Pipa playfighting with a working-class young man during a trampolining lesson, a young man she has previously been sexually intimate with. Drawing on discussions between other young women in the school, Youdell argues that such behaviour would usually be labelled as sluttish, but Pipa is able to side step such judgement, because, Youdell argues, of her social class position. In a recent study of girl-gamers, Beavis and Charles (2007) illustrate how the young women are able to embrace their 'othered' identifies in this male-dominated context. Butterfly, for instance, emphasised her feminine identity by the choice of her on-line gaming name, yet at the same time expressed agency through demonstrating her competence as she beat many of her male opponents. In these two studies, the young women appear able to intentionally step outside the subject positions expected of them (as the girl-gamers do), or take up positions which are not open to other young women (such as Pipa's working-class female peers in the school).

Allen (2008) discusses the concept of agency by drawing on examples from the research process in her study of sexualities in schools. Using a 'photo diary' method (Allen 2008, 568), the research set out to examine the 'sexual culture' of two (state) secondary schools in New Zealand. During the data collection process, Allen found the young research participants actively circumventing some of the stipulations and guidelines of the study when taking their photographs. These included the ethics committee stipulation that photographs should only be taken of 'identifiable people' aged 16 years or over (Allen 2008, 569). Second, one of the schools in which the study took place had a 'five centimetre rule' governing the distance students were expected to keep between each other.

Allen describes how one of the photographs taken for the study by a young research participant was of a young man and woman holding hands, but did not include the couple's faces. Allen argues that the young photographer submitted 'to the authority of the research' $(2008,571)$ by taking a picture encapsulating the topic of the study - sexuality in the school - but at the same time actively flouted the ethical guidelines about only photographing 'identifiable people', and at the same time chose to focus on a direct contravention of school's 'five centimetre rule'. Allen concludes, 'agency is a reworking of the conditions of existence ... not freedom from dominating forces but a double-edged process of submission and mastery' $(2008,575)$.

\section{Agency within a Bourdieuian framework}

In her development of theoretical frameworks which might help us to make sense of changing gender relations, Lois McNay $(2000,2008)$ has engaged extensively with concepts of agency. She criticises Butler's earlier work, arguing 'agency is not only a discursively generated capacity but also a lived relation' (McNay 2008, 163). For McNay, Butler presents us with a 'negative paradigm of subject formation where the individual is conceived as the passive effect of discourse' $(2008,167)$. Instead McNay favours a Boudieuian framework which places the stress on social agents (and not subjects) and works with the notion of praxis - 'living through the embodied potentialities of the habitus' $(2000,40)$. 
Maxwell, C. and Aggleton, P. (2010) 'Agency in action - young women and their sexual relationships in a private school', Gender and Education, 22(3): 327-343.

Bourdieu defines habitus as 'an open system of dispositions that is constantly subjected to experiences, and therefore constantly affected by them in a way that reinforces or modifies its structures' $(1992,133)$. Bourdieu's notion of field places social agents within a particular set of power relations, comprising different spheres of social action (McNay 2008, 182). Reay argues that it is the concept of the field that 'gives habitus a dynamic quality' (2004, 435 ) in that field structures the habitus and the habitus helps constitute the field. 'The logic of the field may reinforce or displace tendencies of the habitus ... it is this tension that is generative of agency' (McNay 2000, 72). Reay concludes, 'when the habitus encounters a field with which it is not familiar, the resulting disjunctures can generate change and transformation' $(2004,436)$.

Several researchers working on issues of gender, class and sexuality have used Bourdieuian concepts in their analyses. Allard wishes to explore the 'complex intersections of power relations and individual agency' $(2005,73)$ in the story of Bluey, a 16-year-old Australian young woman identified as 'at risk' of not completing her education. Using Bourdieu's concepts of capital and field, Allard examines 'which kinds of interactions worked to limit her [Bluey's] access to social capital?' $(2005,72)$ and in which "'fields of action" (i.e. home, school, friends, community) ... was she [Bluey] able to exert a degree of agency and autonomy?' $(2005,73)$. Bluey has a difficult relationship with her family and is viewed by her teachers as a disruptive pupil. Although such circumstances might suggest Bluey has little social capital in both the home and school fields, which is likely to limit her educational progress, Allard illustrates how Bluey accesses new social capitals to overcome the barriers encountered (such as the encouragement she receives from her friends and her boyfriend, and the financial support she obtains through an educational grant). Allard argues that Bourdieu's conceptual tools provide 'a means to better understand how the complexities of social practices, contexts and capital intersect in both productive and inhibiting ways' (2005, 77).

Bullen and Kenway (2005), using data from the same study as Allard, describe a young woman called Alice who walks out of class when she gets angry. They argue that Alice's behaviour can be understood as a form of subcultural capital that so-called 'tough' girls (Bullen and Kenway 2005, 55) who are marginalised and seen to be 'at risk' of failure by the education system, draw upon. Using Alice's own sense-making of her behaviour and thinking about this in relation to Bourdieu's concept of capitals, Alice's walking out can be understood as an act of self-control, or a form of agentic behaviour - which disrupts the relations of power between the student and teacher $(2005,58)$.

Finally, Thomson introduces the idea of a 'logic of sexual practice' $(2000,407)$ to understand differences in attitudes towards sexual experience and early parenthood between two schools - one based in a socio-economically deprived part of England, another in a more economically affluent neighbourhood - 'in terms of the particular economy of values of a community' (2000, 407). Using Bourdieu's concepts, Thomson illustrates how local context can help to make sense of the quite different attitudes held by the young people in these two schools. 
Maxwell, C. and Aggleton, P. (2010) 'Agency in action - young women and their sexual relationships in a private school', Gender and Education, 22(3): 327-343.

\section{Finding new spaces for further theorisations of agency}

Each of the empirical papers discussed above grapples with the concept of agency. Despite drawing on different frameworks, the various authors make similar points: that agency must be contextualised; that everywhere there exist at least moments of agency; and that social class influences and constrains agentic possibilities.

There exist, of course, a number of important pieces of writing on the concept of agency, most notably by various feminist social theorists. Papers critically examine the 'problem of agency in poststructuralist theory' (Clegg 2006, 309; see also The London Feminist Salon Collective 2004) and offer possible ways forward for further theorisations - by extending understandings of the subject within post-structuralism (Davies 1997), or by drawing on theorists from other fields to expand on understandings of agency (Clegg 2006; McNay 2000).

Yet little of this important work actively grapples with empirical data to examine the usefulness and applicability of these ideas for analysing the narratives and social worlds of young women. A notable exception is a more recent paper by Renold and Ringrose, in which the authors use 'Deleuze and Guattari's powerful conceptual repertoire' $(2008,313)$ to examine how the actions of girls and young women rupture the heterosexual matrix. In a smaller field of study examining young women's approaches to and experiences within sexual and intimate relationships - theorisations of agency used tend to be either underdeveloped (Jackson and Cram 2003; Stewart 1999) or situated within a framework (Allen 2003, 2008; Holland et al. 1998) which focuses on identifying behaviours as either resistant to or accommodating of traditional discourses (Maxwell 2007) or 'dominating forces' (Allen $2008,575)$.

Previous work has concluded rather pessimistically that 'few non-traditional attitudes to sexual relationships expressed by young people [are] successfully translated into practice or maintained in real life' (Maxwell 2007, 555). Much current research suggests that agency is usually evidenced in moments of (active) resistance or re-signification. It is imperative therefore to engage empirically in finding ways to identify examples of more sustained agentic practice, as well as exploring possible reasons for such practice becoming embedded. This, we argue, requires us to move beyond the binary that is inevitably created when trying to make sense of young women's actions using Butlerian or Bourdieuian frameworks. The former tend to look to identifying behaviours and speech which suggest possibilities for new subject positions (i.e. those which challenge the dominance of heteronormativity), while the latter offer examinations of how the intersection of capitals and field are either generative or inhibiting of agency.

Even the important contribution made by Renold and Ringrose (2008), who explore what spaces exist for sustained rupture to heteronormativity within girls' and young women's narratives and interactions, appears to frame its findings in binary terms. Similar to Allen (2003), Renold and Ringrose find that ruptures can be swiftly followed by reterritorialisation (often 'of other forms of dominance, differentiation and Otherization'; 2008, 332). The authors also find that the more sustained and multiple ruptures appear to occur mainly within narratives of fantasy - such as about those about imagined futures. While fantasy is a 
Maxwell, C. and Aggleton, P. (2010) 'Agency in action - young women and their sexual relationships in a private school', Gender and Education, 22(3): 327-343.

very interesting space within which resistance can be examined, we were keen to explore examples of agentic practice among the young women in our study that were sustained through time and across different relationships.

In an attempt to move beyond understanding agentic practice as a binary concept, we would therefore like to propose a 'third way' that offers the possibility for looking for more sustained agentic positions within young women's narratives. This approach requires us to focus on understanding how young women position themselves within relationships and to consider how they understand issues of power and control within these. Beyond this, the idea of 'agency in action' may offer a useful way of capturing how young women's reflections on power, and how their experiences of power within relationships, can lead to a radical systematisation of understandings, which may in turn open up possibilities for more sustained agentic practice.

\section{The study}

The findings presented in this paper derive from a study which aimed to explore young women's reflexivity, narratives and embodied practices of agency in their sexual and intimate relationships. Using one private secondary school in England as the research site, young women in their final two years of formal schooling (Sixth Form) were invited to participate in focus group discussions and/or an in-depth interview. The study was undertaken in a private (i.e. fee-paying) co-educational school since a further aim of the overall research, which will be examined in greater depth in another paper, was to explore the extent to which class and socio-economic privilege might influence expressions of agency.

A focus group discussion was organised for interested participants in each of the young women's boarding houses. During the discussions a series of vignettes from previous research were drawn on to stimulate debate on young women's sexuality and their experiences of relationships. Following the group discussions, e-mails were sent to all young women in the Sixth Form inviting them to take part in an in-depth interview. The interviews focused on young women's own intimate relationship and sexual experiences - asking them to recall both positive and negative instances within these, and by reflecting on their past experiences asking them to articulate their hopes and aspirations for the future. All the discussion groups and interviews were facilitated by the first author over an in-depth period of four months. In total 54 young women took part in the study, 31 of whom discussed their own experiences of sex and intimate relationships in an in-depth interview context. All participants were invited to identify a pseudonym for the study. The young women were aged between 16 and 18 years and all were white, with a small number having grown up abroad but with UK family connections.

Focus group discussions and interviews were audio-recorded with permission and then verbally transcribed. The process for identifying and categorising sections of narrative as potentially indicating some sort of agency was not a straightforward process. We began therefore with a close reading of the transcripts, attempting to initially stay close to the expressions used and emphases placed by the young women themselves in their narratives. This process generated a range of potential themes such as: I decide what happens; I am 
Maxwell, C. and Aggleton, P. (2010) 'Agency in action - young women and their sexual relationships in a private school', Gender and Education, 22(3): 327-343.

strong, therefore I need a strong/dominant man; he is more committed to this relationship than me, therefore I wear the trousers; at our age we should be having fun; and he is complicated and needs me. Finally, a significant number of young women appeared to talk rather ambivalently about some relationships or described themselves as having what might appear to be a 'fickle' attitude to relationships. Within these themes, we drew out how young women talked about or made indirect reference to the notion of power within relationships, and then tried to identify agentic practice with these understandings of power at the forefront.

\section{Power in relationships}

As McNay has said, 'practice is both the product of power relations that have been internalised into the body and also an active engagement with social structures' $(2008,185)$. This section of the paper focuses on how young women directly or more indirectly appeared to conceptualise power and power relations in their sexual and intimate relationships. We believe, as McNay (2008) does, that the starting point for developing understandings of agency must be an examination of the concept of power.

By focusing on young women's conceptualisations of power we have aimed to trace emotional responses, articulated reflections, statements of intent or of desire to respond to these power relations - thereby beginning to identify examples of agentic practice. As we wish to avoid, as we see it, the constraints of analysing empirical data within a specific theoretical framework, we have approached the reading of young women's conceptualisations of power in a relatively open manner. This starting point does not mean we believe young women's narratives to reflect any particular truth, but that their articulations of power are likely to be linked in some way to how they describe and make sense of practices within their sexual and intimate relationships. It is the process of tracing through from young women's descriptions of power relations within relationships, to their reactions and behaviours, which we argue may offer a 'third way' of developing understanding of agentic practice.

Many young women in the study aligned the concept of power with not having 'choice' (Letita) or alternatively with being in 'control' (Mercedes).

At the beginning like, I had to be, like [to her boyfriend], 'You need to take more control over the situation, of our relationship', because, well not control, but if someone doesn't have more control over me then I'll just walk all over them. And now he's like, he's absolutely fine with that. (Sarah)

Sarah went on to describe how her and her boyfriend used to,

Have like play fights ... and I'd push him ... [or] I'd like hit him like that [demonstrates slapping his upper body] and he wouldn't stop me. And l'd be like, 'Why don't you stop me?' And I was really blunt ... I told him to tell me to, 'Fuck off', if I'm being annoying. (Sarah) 
Maxwell, C. and Aggleton, P. (2010) 'Agency in action - young women and their sexual relationships in a private school', Gender and Education, 22(3): 327-343.

Here Sarah, while positioning herself as the one in 'control', describes telling her boyfriend to take more charge of the situation and to take some of the control back - in this instance, by chastising her for hitting him. Sarah here appears to suggest that she needs her control or power to be restrained, otherwise she may well abuse her position by 'walk[ing] all over' men. Sarah's description of power within an intimate relationship implies it is strong, an almost unruly, sometimes violent thing. She also suggests that power is a continuum in which one partner can have more power than the other, or that an equilibrium can be found - 'now he's like he's absolutely fine with it'. Striving to achieve a balance of power within a relationship, at least in some parts of a relationship, was mentioned by other young women in the study, examples of which are given further below.

While Sarah describes being the person in a relationship who has the control, a more common refrain in the young women's narratives was about being unable to manage or contain the power a young man had over them.

He's still a bit of an arsehole [her previous boyfriend] but ... there's always a bit of me [when] he turns on the charm and I still kind of fall for it. Because he is really good looking. (Ellie)

Here, Ellie who described her current relationship as one in which she wore the 'trousers', talks about how her ex-boyfriend continues to have a hold over her, despite her realisation that he is 'a bit of an arsehole'. Similarly, Fanny spent most of her interview discussing a protracted relationship she had had with a boy from her school, because she appeared to be powerless to stop herself 'getting drawn back' to him, although she knew he was 'wrong' for her.

Despite such stories, close to half of the sample - like Sarah above - described themselves as the ones in control of their relationships.

'Cos I know for a fact that I wear the trousers in the relationship, and I kind of do whatever I want to do. And he gets a lot of stick from the boys, 'Ooh being under the thumb' ... he genuinely thinks I think that I'm out of his league. (Ellie)

Young women felt they held power over partners because they described boyfriends as being more committed to, or more 'needy' of the relationship - which placed them in a position of power.

I think I'm not quite so bothered as he is. But I think that's been the same throughout our whole relationship. He like, when we started going out, he was always, I think a lot more liked me a lot more than I liked him ... definitely yeah he is slightly more committed to the relationship, more than me. (laughing) (Sally)

'Cos I'm like the girl, I could get in a stress for no reason, and it would be his fault kind of thing, do you know what I mean? ... I had a bit of control because he was so like protective, it was just like that. But with sex it wasn't at all like, it was very equal. He wasn't, he'd never pressure me and I never pressured him. (Liz) 
Maxwell, C. and Aggleton, P. (2010) 'Agency in action - young women and their sexual relationships in a private school', Gender and Education, 22(3): 327-343.

Here, Liz suggests that the balance of power can be variously distributed across different areas of a relationship. Whereas her boyfriend appeared to just accept her 'getting in a stress for no reason', when it came to having sex, Liz felt that neither partner took advantage of the other.

The second significant way in which young women conceptualised power was as a position they could simply occupy - i.e. be powerful. Here, Mercedes is advising her sister, whose marriage recently ended and who has just started to meet potential new partners:

I was just like you know, 'Play hard to get, you know, he [one potential new boyfriend] really liked you and the reason he went off you is 'cos you weren't playing hard to get' ... So I had to teach her how to play hard to get. I think the only way to ever get a guy to like you is to play hard to get and be in control. And maybe it's just me but it's worked for me, so... (Mercedes)

Later, Mercedes described an incident with her recent ex-boyfriend, in which she demonstrates taking control of the situation:

Towards the end [of the relationship], I just stopped fancying him and we stopped having sex, and he made a comment ... [and] we got in a massive fight, I said, 'I'm not having sex with you for a couple of weeks, 'cos we got in a fight', and he said, 'Oh that doesn't make any difference, that's not much change'. So I thought, 'Well that's it'. And then we were in bed together just going to sleep and then he thought I was cheating on him with X, the guy from the holiday actually ... which I wasn't. And we got in a fight and he hit a wall and put a hole in the wall. And so I thought, 'Right, you're getting aggressive around me, it's not on', so I broke up with him. (Mercedes)

Mercedes illustrates the two main conceptualisations of power in relationships offered by young women in this study - a position which partners have to vie for within their relationship ('[need] to be in control') or it is a position which can be simply occupied - I am a powerful person ('it's just me'). What possibilities for agentic practice do such understandings of power open up?

\section{Reacting into action - taking power back}

One of the most common ways in which young women described taking action was when they reacted emotionally to an experience, which spurred them to change course. Letita explained that after having had sex with one of her brother's friends when she was drunk, she had 'felt really dirty'.

I kind of made a rule for myself [after this experience] to never do anything unless I actually like the person, because I just hate feeling bad about myself. (Letita)

Fanny told about one incident which had occurred during her protracted on-off relationship with her ex-boyfriend. She explained that her ex-boyfriend had told her he had split up with his current girlfriend, and that they were therefore free to have sex. But in fact, he had not broken off his current relationship, so when his girlfriend had found out about him and 
Maxwell, C. and Aggleton, P. (2010) 'Agency in action - young women and their sexual relationships in a private school', Gender and Education, 22(3): 327-343.

Fanny having had sex, the girlfriend had turned on Fanny calling her 'names' and saying 'I have no morals and stuff'. Fanny reflected:

I think I almost needed someone like that [her ex-boyfriend's girlfriend to shout at her] 'cos ... I'd always be drawn back to him, and I needed someone like that for it to end so nastily so that I could ... sort of realise that if I did get myself into that situation [again where he is trying to have sex with me] I'd break it off like as soon as I could ... because none of it was worth ... the end result kind of thing if that makes sense? (Fanny)

Fanny went on to confirm that she had had nothing to do with her ex-boyfriend again.

Letita and Fanny described how they came to a decision about future actions on the basis of 'emotional' responses to experiences they had just had. Similarly, Mercedes earlier had decided to end the relationship with her boyfriend after he had punched a hole in a wall because she became indignant about his behaviour. These emotions had led her to take control of the situation - take power back. Was it easier for young women like Mercedes to take power back because they positioned themselves as being in control within their relationships?

Sally also suggested she held more power because 'I'm not quite so bothered as he is' about the relationship. Here, she describes setting down conditions for the relationship to continue after her boyfriend admitted kissing another young woman on a drunken night out.

I made of a point that he had to make more of an effort with me ... initially I don't think, we kissed or anything for a couple of days afterwards, or not properly ... I mean, to be honest, it was only a week that [she did not let him kiss her] it wasn't really. But then, it just, you know ... But for me that week was quite important. (Sally)

Yet taking power back also appeared to take place in relationships where young women did not describe themselves, at least overtly, as being in control in this kind of way. Furthermore, becoming more powerful in a relationship need not always be a reaction to a negative (emotional) experience. Here, Jude describes becoming a more equal partner in the sexual part of her relationship over time.

Claire: And how has that [the sexual side of your relationship] kind of developed? Has that been you kind of wanting that to develop and having that feeling inside you of wanting to explore that? Or has that to some extent been led by $X$ [her boyfriend], or guided by him because he's the older, perhaps more experienced guy? I don't know, you know, just tell me a bit about that...

Jude: Well obviously I wanted to kind of you know explore it [sex] and become more ... I don't know, into it or ... I can't think of the right word. But also in some ways when we started having sex he had had sex before and I was doing it for the first time, so he was kind of like, 'You do things this way'. And like it was inevitable that he was going to have to teach me things, 'cos he'd done it before and I hadn't. It was silly me kind of fumbling my way through 
Maxwell, C. and Aggleton, P. (2010) 'Agency in action - young women and their sexual relationships in a private school', Gender and Education, 22(3): 327-343.

things. But um ... now I feel like ... I don't know, l'd never feel like he was more experienced than me or anything like that.

Jude continued by explaining that over time she began to,

Suggest things that might kind of you know liven things up, or ... you know just change things in a better way or something. Or like ... I don't know like ... just kind of experimenting, see how things work. (Jude)

Here, Jude suggests that she felt a growing confidence, and an interest and willingness to perhaps take power back from her boyfriend, who had previously taken on the role of initiating sex. Jude also intimates she decided she wanted to be a more equal partner in that aspect of their relationship.

However, another way of looking at this same account, especially given Jude's active positioning of herself as suggesting 'things' to do sexually and wanting to experiment, is that Jude understands power not as a relational concept, but simply a position she can occupy (when she is ready or when she feels like she wants to). She can take power, be powerful as she goes on to do in their sex life - rather than having to wrestle it back, to the detriment of her boyfriend.

\section{Agentic positions - being powerful}

In the previous section, young women described realising a more powerful position within their relationships vis-à-vis their partner, usually as a result of strong emotions having provoked a motivation for change. Their narratives often conceptualise power as a resource that must be divided between partners in a relationship (usually unequally).

However, some young women in the study also portrayed power as a position they could occupy without resistance (see Mercedes and Jude for instance). Taking up such a position seemed to be achieved in four possible ways: via an 'I decide' attitude; through having 'confidence'; by being 'a strong, powerful person'; and by being 'ambivalent' towards relationships and/or sex.

The majority of young women in the study used a very active, 'I decide' voice when describing many of their relationship interactions. Dot, despite her boyfriend's pleas, said she knew their relationship would have to end when they left school.

Although I sort of thought, 'Well why not enjoy it till it's [the school year] over' ... he was really serious and said, 'Well what about ... can we be together in our gap years and at uni?' and I sort of said, 'no' ... I tried to say to him that we should just have a good time to the end. But he felt that he couldn't do that unless he knew that it wasn't going to end. I felt that I couldn't say that. (Dot)

Here, Dot appears to take an active position in the way she manages the situation. 
Maxwell, C. and Aggleton, P. (2010) 'Agency in action - young women and their sexual relationships in a private school', Gender and Education, 22(3): 327-343.

Similarly, Chantelle, although she reflected on how well her current relationship was going, explained that due to a previous arrangement she had made with her cousin to 'go crazy this summer', she was unable to commit to remaining faithful to her boyfriend over the long summer holidays.

He [her boyfriend] said to me he's not going to do anything [this summer], so that puts me in quite an awkward position because I'm going to be, I'll have so many opportunities to [get sexually intimate with someone]. And it was going to be, that was sort of my plan me and my cousin going out, we're going to go crazy this summer ... I think it's just going to develop how it comes, I'm just going to see how it comes, how I feel, if I do it, when it comes to situation make decisions then. (Chantelle)

Taking up a position of being powerful was described by some young women in the study as being strongly linked to the notion of confidence.

I haven't really had the confidence to do anything about it since, so... (Anne)

Anne suggests that action (i.e. doing something about 'it', in this case, finding another boyfriend after being publicly humiliated by a young man she was interested in) requires confidence. Ellie and Bella described having a confident attitude to their sexuality and to sex which meant they actively initiated experiences with their partners.

There's a whole new sort of side to me that came out [since being with her current boyfriend], it was just like, I've not really had that before, before I was just erm ... [now] I do stuff that I never, I send him dirty text messages, [before] I would be so, 'Oh that's so shocking' you know, [I do] funny odd [sexual] positions... (Ellie)

I used to find quite a lot that I'd initiate it and he wouldn't want to [have sex] ... which I found weird. (Bella)

A third way in which participants suggested they were able to be powerful was through their own (strong) personalities. Like Sarah, discussed earlier on in the paper, Letita and lona reflected on how their 'personalities' meant they could not, and would not, be in a relationship with someone who did not match them in terms of personality or strength of character.

Because I'm quite like a strong person and I can't cope with like weak people that agree with me and stuff like that $-I$ just get really really irritated ... there needs to be some physical attraction and then just banter [combative talk] ... like I was seeing this guy a few weeks ago and then, like ... he supposedly really likes me, but he kept agreeing with everything that I said and it was just all like ... no, don't, take the piss out of me, I just couldn't really cope with it so I sort of stopped that [the burgeoning relationship]. (Letita)

I just hate people that have no backbone, and I'd much prefer ... I want my boyfriend to be like [to] get angry with me if I do something and not be scared of me ... 'cos I 
Maxwell, C. and Aggleton, P. (2010) 'Agency in action - young women and their sexual relationships in a private school', Gender and Education, 22(3): 327-343.

can be quite scary, I know I can be quite scary. 'Cos I'm quite open, I'm quite confident, I don't keep anything to myself. So I much prefer someone that has a bit of a backbone and says, 'Oh shut up'. (Iona)

Here, Letita and lona both portray themselves as forces to be reckoned with - as young women whose own needs and views are at the forefront of decision-making within relationships. Both Letita and lona suggested this strength was part of their personality.

Finally, although perhaps a little counter-intuitive, several of the young women in the study appeared to occupy positions of power because of their ambivalent attitude to the management of their relationships. These young women put themselves and their own needs at the centre of their interactions with others, liked to be powerful, and reacted quickly and honestly to their own emotional responses to people and situations.

Barbara: I'm really really fickle, is that the right word?

Claire: Yeah.

Barbara: I like someone, then I don't, and then I like someone and then I don't. I like loads of people and then like as something might happen with them I'm like, 'No I don't want to'. And like everyone kind of knows me for sort of being really bad like that.

Serially moving between boyfriends was a strategy also described by Mercedes.

I started going out with this guy called ' $X$ ' who I've been with for a year and a half. But I broke up with him because I started seeing someone else, and then we got back together. And then I broke up with him and then I started seeing someone else. Now we're kind of going to get back together ... I don't know... (Mercedes)

Fickleness was most commonly illustrated by not wanting to stay in a particular relationship for very long.

It only works for about six months, because I always want ... I'm always looking for something else. I think that's me as a person. I mean, I can be very content and like I am a content person, but I don't like to stick to one thing, I think that's really mundane and like I'd rather yeah have my options open. And I don't ... I think the problem with me in a relationship is I don't like being told what to do, I don't like having restrictions. (Mercedes)

Chardonnay explained that she moved from one relationship to another probably because,

People that are in serious relationships I just couldn't, I'm not sure I could be bothered, like I prefer to have like fun. Rather than like getting stuck down ... I don't think I've ever been really upset about something in a relationship. (Chardonnay)

While ambivalence or fickleness towards relationships and interactions with young men could be viewed in a negative light - these same narratives evidence young women's active approach to and engagement with their experiences. If a respondent got bored - she moved 
Maxwell, C. and Aggleton, P. (2010) 'Agency in action - young women and their sexual relationships in a private school', Gender and Education, 22(3): 327-343.

on and found someone better. This suggests an honesty and an agency in the way young women actively listened to, and responded to, their emotions.

\section{Discussion}

Young women in the study appeared to understand both power and control as a usually unequally distributed resource. In this first conceptualisation of power, young women described a relational concept of power as something that underpins interactions. Young women recognised inequality of power within intimate relations, but also identified it as a positive resource - providing examples of how they or their partners mobilised this fluid, discursive resource in their practices. In engaging with this framing of power, respondents most often described situations in which they felt upset or got angry (usually because they had experienced an inequality of power) indicating that the recognition of such emotions led to an agentic response. As McNay $(2008,185)$ has put it, drawing upon Burkitt (1997), 'spontaneous emotions experienced in their relationship to a situation or another person ... can be generative ... [and] override the entrenched dispositions of actors, pushing them to unexpected or nonconformist types of actions'. This finding points to the importance of emotion and 'emotion work' (Duncombe and Marsden 1998) in the working up of agency among young women. But it also calls for a degree of systematisation of insight into the cause of being upset or feeling angry. Such a systematisation of insight, at the discursive if not at a conscious level, we believe is central to developing more sustained agentic practice.

Natalia, for example had decided she did not enjoy oral sex. The physical revulsion, 'it just makes me sick', meant she would under no circumstances agree to perform oral sex. Consequently, if she felt a boyfriend was pressuring her to give him oral sex, she ended the relationship.

Natalia: $\quad \operatorname{Er}$... no I hate ... going down on the guy [giving oral sex], I don't like that at all, I don't think that's very nice.

Claire: Do you like a guy going down on you?

Natalia: $\quad$ Yeah it's all right, I just cannot stand doing something to him. It just makes me sick and my old boyfriend didn't actually mind, so he was like, 'I don't care', so that was nice.

Claire: $\quad$ So it was alright. So did you kind of say to him, 'Listen, I don't like this at all'?

Natalia: $\quad$ Yeah, but $X$ [another ex-boyfriend] was really up for me doing it, and that's why I didn't like go out with him anymore, I was just like, 'No thanks'.

Natalia suggests here that her decision not to perform oral sex on a boyfriend had been sustained across a number of relationships.

Ellie offered another example of how an emotional response can lead to a systematisation of the reason behind this response, the development of an understanding of whether being made to feel like this is acceptable or not, and then 'agency in action'. In the following example, Ellie's anger at her boyfriend's repeated jealous behaviour ('it always starts when 
Maxwell, C. and Aggleton, P. (2010) 'Agency in action - young women and their sexual relationships in a private school', Gender and Education, 22(3): 327-343.

he gets drunk') led her to set out conditions for their relationship to continue. Ellie explained how they were out at a night club with some of her school friends,

He was drunk and like really drunk, and it always starts when he gets drunk. It really annoys me ... he was just an absolute arsehole, and he was trying to like dance with me. And I was like, 'I want to stay with my friends' kind of thing, and he was like, 'Oh you like your friends more than me', oh for God's sake! ... [he said], 'Oh fuck, I'm going to go and try it on with $X$ [one of her friends] then'. And I H-I-T the roof, I was fuming. I mean we had this big thing [fight] and he was just being so, so irritating ... he got so angry and he threw his phone on the floor and it smashed, it still worked. But then he put it [the phone back] together and did it again [smashed the phone on the floor] and then we were outside the club afterwards and I was like, 'Get in the taxi with us and we'll go home, I'll drop you home'. And X [her male best friend] was staying at my house that night and he [her boyfriend] was like, 'Can't you stay at my house', and I was like, 'No, I'm not going to stay at your house' ... I was just so angry with him. And so I made him stop drinking for two months (laughs). (Ellie)

Thus, one of the main ways in which the young women in this study demonstrated 'agency in action' was after an emotional response to an experience in which they felt someone else had power over them, or was attempting to control them. In the examples above, young women recognised certain conditions or experiences they were unwilling to have repeated, and incorporated the lessons learned into their future practice - pointing to possibilities for sustained 'agency in action'.

However, a second notion of power identified within the study offers an important way of further developing understandings of how agentic practice within relationships might take place. Young women in this research described themselves as powerful, and as being able to occupy such a position within their relationships without the anticipation of much resistance. Feeling powerful, understanding and describing your personality as being powerful and strong, and being able to retell experiences in which you positioned yourself as in control, may offer some of the young women in the study the possibility of being agentic in a more sustained way over time and across their relationships. Such a discursive positioning may lead young women to believe emotionally that they are powerful, which in turn reinforces their approach to sexual and intimate relationships and the way they respond to partners' behaviours and expectations. Mercedes, for instance, saw herself as being powerful. While Mercedes provided examples of situations in which one could argue her boyfriends were trying to assert (violent) control, as in the instance where her boyfriend punched through a wall when he believed she was being unfaithful to him, Mercedes nevertheless positioned herself as if she was the one in control, which may be one of the reasons why, during her interview, she continuously described how she actively decided on what course of action to take in her relationships. In such a conceptualisation of agentic practice, young women's openness towards their own emotions also played a role - as young women 'listened to their feelings' when making decisions (anger and fright in the example Mercedes gave above), or stuck to their original plans even when this might hurt their partners' feelings (as Chantelle and Dot did with regards to their summer and postschool plans, respectively). 
Maxwell, C. and Aggleton, P. (2010) 'Agency in action - young women and their sexual relationships in a private school', Gender and Education, 22(3): 327-343.

Alongside the importance of emotions, two further elements provide important ways in which we must continue to develop the concept of 'agency in action'. The first is the way in which young women's views of their bodies and the way their bodies became part of their intimate and sexual interactions, may have constrained or facilitated agentic practice. The second element to consider is the influence of socio-economic class and privilege on the way in which some of the young women in this study positioned themselves as active, powerful and as able to make their own decisions.

Within sexual and intimate relationships, the body arguably plays a significant role. Young women's often conflicted relationships with their bodies (Budgeon 2003) and the long history of research which has recorded the so-called 'missing discourse of desire' among young women (Fine 1988; Tolman and Szalacha 1999) might suggest that agency in bodily practices may be limited. Yet, in more recent research, scholars in the field of sexuality and intimacy are challenging this view. Bryant and Schofield, in their work with older women, concluded that 'sexually embodied practice, according to the women's descriptions, produces diverse experiences, including joy, exhilaration, confusion, pain ... and transcendence. These ... shape ... and fuel the kinds of sexual relationships and identities they pursue' (2007, 337). Westhaver, through his research with gay men attending commercially organised dance parties, similarly argues that 'bodily gestures ... evoke or create new semblances of the world, as gestures that create insight and empowerment for the actors involved' $(2006,636)$.

Some of the young women in our study lacked confidence in their bodies, while others did not; some young women were quite ambivalent about sex and having feelings of desire, while others articulated quite vivid experiences of sexual desire and pleasure. A greater focus on the role of the body and the experiences of physical sensations within sexual and intimate relationships and how these might link to the understanding of agency we have developed in this paper, will be explored in a further paper.

The privileged socio-economic class position of the young women in the study is also worthy of further analysis. While studies of children and young people in mixed-class environments have suggested that privilege enables young women to 'exceed the bounds of the prevailing discourse of hetero-femininity' (Youdell 2005, 267), in previous work on young women's management of sexual and intimate relationships we have questioned the extent to which class matters (Maxwell 2006) [1].

Finally, a third set of issues which we would like to consider to greater depth in a future study is the way in which agentic practice is evident and shows some sustainability across the various domains, not only of their sexual and intimate relationships, but also across girls' relationships with school, their families, their friends and in their engagement with their futures. 
Maxwell, C. and Aggleton, P. (2010) 'Agency in action - young women and their sexual relationships in a private school', Gender and Education, 22(3): 327-343.

\section{Conclusion}

In the broader literature on gender and sexualities, there exists a tension between building upon existing theory and not closing down too early the possibilities for innovative analysis. As Atkinson and de Palma argue in their work on the 'operation of heteronormativity in educational contexts' $(2009,17)$, through the process of 'naming and believing the heterosexual matrix and identifying evidence of its operation, we reify, reinforce and reinscribe it, even as we attempt to subvert, unsettle or deconstruct it' $(2009,17)$. Our approach in this paper has been to explore understandings of agency and agentic practice through what we have suggested may be a 'third way'. Echoing Atkinson and de Palma's (2009) call for caution, we have been anxious not to close down possibilities for identifying new forms of agency in young women's narratives and the practices they describe. This third way of identifying and understanding 'agency in action', as we call it, begins with young women's conceptualisations of power within relationships and traces the struggles in which they have participated, and the elements of radicalism in the agentic practice they display. Such an approach, we believe, holds the potential to identify when young women have systematised understandings of power, which may lay the foundations for more sustained forms of agentic practice.

\section{Acknowledgements}

This study was funded by a grant from the UK Economic and Social Research Council (RES000-22-2398). The views expressed are those of the authors alone. Earlier versions of this paper were given at the Faculty of Education EED Youth Studies Seminar Series, Cambridge University, 10 February 2009 and at the British Sociological Association Annual Conference, Cardiff, 17 April 2009. We would also like thank the two anonymous reviewers for their useful comments and reflections.

\section{Note}

1. Although a more focused analysis of the links between privilege and agency will be the focus of a further paper, an initial examination suggests that the 'top girl' media discourse discussed by McRobbie (2007) and others (such as Harris' future girl, 2004) which to a large extent does encapsulate many aspects of the young women's lives, suggests that class is likely to play an important role in facilitating the kinds of active, 'in control' and 'I decide' voices many of the young women used in their narratives. Such a discursive positioning, we argue, influences their practices within intimate relationships. Yet, a number of other factors within many of the young women's lives also calls for a strong note of caution when making the assumption that privilege links to agency in an uncomplicated way. The very traditional structure of so many of the young women's families (mothers as the homemakers and fathers out at work, an arrangement many of the young women expected to reproduce in their own futures); the tightly regulated discourse of heteronormativity that pervaded the school's culture; and the hectic pace of the young women's lives, which meant few had time to reflect on their experiences 
Maxwell, C. and Aggleton, P. (2010) 'Agency in action - young women and their sexual relationships in a private school', Gender and Education, 22(3): 327-343.

and process emotions, suggests agency may not necessarily be so clearly linked to socioeconomic privilege.

\section{References}

Allard, A. C. 2005. Capitalizing on Bourdieu: How useful are concepts of 'social capital' and 'social field' for researching 'marginalized' young women?. Theory and Research in Education 3, no. 1: 6379.

Allen, L. 2003. Girls want sex, boys want love: Resisting dominant discourses of (hetero) sexuality. Sexualities 6, no. 2: 215-236.

Allen, L. 2008. Young people's 'agency' in sexuality research using visual methods. Journal of Youth Studies 11, no. 6: 565-577.

Atkinson, E and R. de Palma. 2009. Un-believing the matrix: Queering consensual heteronormativity. Gender and Education 21, no. 1: 17-29.

Barnes, B. 2000. Understanding agency: Social theory and responsible action. London: Sage.

Beavis, C. and C. Charles. 2007. Would the 'real' girl gamer please stand up? Gender, LAN cafés and the reformulation of the 'girl' gamer. Gender and Education 19, no. 6: 691-705.

Bourdieu, P. 1992. An invitation to reflexive sociology. Cambridge: Polity Press.

Budgeon, S. 2003. Identity as an embodied event. Body and Society 9, no. 1: 35-55.

Bullen, E. and J. Kenway. 2005. Bourdieu, subcultural capital and risky girlhood. Theory and Research in Education 3, no. 1: 47-61.

Butler, J. 1990. Gender trouble: Feminism and the subversion of identity. London: Routledge.

Butler, J. 1997. Excitable speech: a politics of the performative. London: Routledge.

Clegg, S. 2006. The problem of agency in feminism: a critical realist approach. Gender and Education 18, no. 3: 309-324.

Davies, B. 1997. The subject of post-structuralism: A reply to Alison Jones. Gender and Education 9, no. 3: 271-283.

Duncombe, J. and E. Marsden. 1998. 'Stepford wives' and 'hollow men'? Doing emotion work, doing gender and 'authenticity" in intimate heterosexual relationships. In Emotions in social life - critical themes and contemporary issues, eds. G. Bendelow and S. J. Williams, 211-227. London: Routledge.

Emirbayer, M. and A. Mische. 1998. What is agency? The American Journal of Sociology 103, no. 4: 962-1023.

Fine, M. 1988. Sexuality, schooling, and adolescent females: The missing discourse of desire. Harvard Educational Review 58, no. 1: 29-53. 
Maxwell, C. and Aggleton, P. (2010) 'Agency in action - young women and their sexual relationships in a private school', Gender and Education, 22(3): 327-343.

Foucault, M. 1990. The history of sexuality, Volume 1: An Introduction. (trans. Hurley, R.). London: Penguin.

Harris, A. 2004. Future girl: young women in the twenty-first century. London: Routledge.

Hitlin, S. and G. H. Elder Jr. 2007. Time, self, and the curiously abstract concept of agency. Sociological Theory 25, no. 2: 170-191.

Holland, J., C. Ramazanoglu, S. Sharpe and R. Thomson. 1998. The Male in the Head-young people, heterosexuality and power London: the Tufnell Press.

Jackson, S.M. and F. Cram. 2003. Disrupting the sexual double standard: Young women's talk about heterosexuality. British Journal of Social Psychology 42, no. 1; 113-127.

Maxwell, C. 2006. Understanding young women's sexual relationship experiences: The nature and role of vulnerability. Journal of Youth Studies 9, no. 2: 141-158.

Maxwell, C. 2007. 'Alternative' narratives of young people's heterosexual experiences in the UK. Sexualities 10, no. 5: 539-558.

McNay, L. 2000. Gender and agency: reconfiguring the subject in feminist and social theory. Cambridge: Polity Press.

McNay, L. 2008. Beyond recognition. Cambridge: Polity Press.

McRobbie, A. 2007. Top Girls? Young women and the post-feminist sexual contract. Cultural Studies 21, nos. 4-5: 718-737.

Reay, D. 2004. 'It's all becoming a habitus': Beyond the habitual use of habitus in educational research. British Journal of Sociology of Education 25, no. 4: 431-444.

Renold, E. and J. Ringrose. 2008. Regulation and rupture. Mapping tween and teenage girls' resistance to the heterosexual matrix. Feminist Theory 9, no. 3: 313-338.

Sewell, W. H. 1992. A theory of structure: Duality, agency, and transformation. The American Journal of Sociology 98, no. 1: 1-29.

Stewart, F.J. 1999. Femininities in flux? Young women, heterosexuality and (safe) sex. Sexualities 2, no. 3: $275-290$.

The London Feminist Salon Collective. 2004. The problematization of agency in postmodern theory: As feminist educational researchers, where do we go from here?. Gender and Education 16, no. 1: 25-33.

Thomson, R. 2000. Dream on: The logic of sexual practice. Journal of Youth Studies 3, no 4: 407-427.

Tolman, D. L. and L. A. Szalacha. 1999. Dimensions of desire. Bridging qualitative and quantitative methods in a study of female adolescent sexuality. Psychology of Women Quarterly 21, no. 1: 7-39

Youdell, D. 2005. Sex-gender-sexuality: How sex, gender and sexuality constellations are constituted in secondary schools. Gender and Education 17, no. 3: 249-270. 
Maxwell, C. and Aggleton, P. (2010) 'Agency in action - young women and their sexual relationships in a private school', Gender and Education, 22(3): 327-343.

Youdell, D. 2006. Subjectivation and performative politics-Butler thinking Althusser and Foucault: intelligibility, agency and the raced-nationed-religioned subjects of education. British Journal of Sociology of Education 27, no. 4: 511-528. 